\title{
Prevalence and associated factors of elder abuse in a community-dwelling population of Aotearoa New Zealand: A cross-sectional study
}

\author{
Polly Yeung, Lareen Cooper, Michael Dale
}

Polly Yeung is the Senior Lecturer in the School of Social Work and also a research team member of the Health and Ageing Research Team (HART) at Massey University, Palmerston North. Lareen Cooper is the Associate Head of School of Social Work at Massey University, Palmerston North. Michael Dale is the Senior Lecturer at the School of Social Work, Massey University, Palmerston North.

\section{Abstract}

The purpose of this cross-sectional study was to investigate the prevalence and associated factors of elder abuse in a representative sample of older people in Aotearoa New Zealand. Analysis was conducted on responses from the second wave of the New Zealand Longitudinal Study of Ageing (NZLSA) omnibus survey of 3,923 adults aged 50-87 years. Using the elder mistreatment screening questions, the sample was split between those who identified of having experienced elder abuse $(n=529)$ and those who did not $(n=2417)$ from a large population-based study to compare on 19 variables (i.e. age, gender, marital status, living arrangement, education levels, ethnicity, personal income, total number of health conditions, physical health, mental health, ability to get around, economic wellbeing, loneliness, social and emotional loneliness, depression, happiness, satisfaction with life and quality of life). Significant differences were found on 16 of the variables assessed. Results suggested that those who have experienced elder abuse had a higher level of loneliness and poor economic wellbeing. They were more likely to experience depression, have poorer mental health and be less happy. The experience of abuse had significant impact on their satisfaction with life and overall quality of life. A better understanding of these risk factors associated with elder abuse in aging population will assist with both prevention and intervention.

\section{Introduction}

Older people are the fastest growing segment of the population world-wide (The World Health Organisation, 2012). With this trend comes the potential for increased rates of elder abuse. Elder abuse is not a new problem (Baker, 1975; Burston, 1975) and has now been recognised as a problem of epidemic proportions (Kosberg \& Garcia, 1995; Lowenstein, Eisikovits, Band-Winterstein \& Enosh, 2009; Poole \& Rietschlin, 2012). According to the World Health Organisation (2002), the prevalence of elder abuse in developed countries ranges from $1 \%$ to $10 \%$. Elder abuse has been linked to increased risks of morbidity and mortality (Dong, Beck \& Simon, 2009; Lachs, Williams, O’Brien, Pillemer \& Charlson, 1998). The prevalence of abuse in community settings is reported to range from $6 \%$ of older persons in the community who are likely to have experienced significant abuse in the last month 
(Cooper, Selwood \& Livingston, 2008) to Lachs and Pillemer (2004) who support the lower end of this rate for abuse occurring in the community. Typically, studies produce widely divergent estimates, influenced by definition, culture and methodological issues (Lindert et al., 2013). Age Concern (2005) in New Zealand suggests that between three and 10 percent of elders may be subjected to elder abuse and neglect. The purpose of this cross-sectional study utilising the NZLSA, is to investigate the prevalence and associated factors of elder abuse in this representative sample of older people in Aotearoa New Zealand. The aim of this study is to raise awareness within community-based health and social services personnel in New Zealand of risk factors for abuse and neglect amongst elders living in the community.

\section{Literature review}

A review of both international and New Zealand literature is presented in relation to three themes: (1) issues regarding the definition of elder abuse; (2) obstacles to the disclosure of abuse by older persons; and (3) the scope and correlates of elder abuse.

\section{Issues surrounding the definition of elder abuse}

A consistent theme in the literature on elder abuse, neglect and mistreatment is the difficulty of definition (Lachs \& Pillemer, 2004). Lack of agreement about the definition and its parameters has made the assessment of prevalence and incidence problematic from an empirical perspective (Harbison \& Morrow, 1998). It makes it especially difficult to determine the extent of the problem of elder abuse. In Canada, Great Britain and Finland, prevalence rates of elder abuse were found between $4 \%$ and $6 \%$ while a rate of between $1 \%$ and $10 \%$ was estimated in the USA (Griffin, 1994; Pillemer \& Finkelhor, 1988). Elder abuse can take the form of physical, emotional, psychological and sexual abuse, financial exploitation, passive and active neglect by a caregiver, domestic violence and healthcare fraud (National Centre on Elder Abuse, 2005; Shilling, 2010). The World Health Organisation published the Toronto Declaration on the Global Prevention of Elder Abuse which stated 'elder abuse is the violation of human rights and a significant cause of injury, illness, lost productivity, isolation and despair. Confronting and reducing elder abuse requires a multi-disciplinary approach' (The World Health Organisation, 2002, p. 3). Age Concern New Zealand (Age Concern New Zealand Inc., 2005, 2006) defines elder abuse and neglect as usually committed by a person known to the victim and with whom they have a relationship implying trust. According to Age Concern New Zealand, four main types of elder abuse occur: physical abuse (the abuser may inflict physical pain or injury or use force on a victim; psychological / emotional abuse (behaviours by the abuser which cause the victim anguish, stress or fear); financial abuse (such as the illegal or improper exploitation and use of funds or other resources); and sexual abuse (such as threat, forced engagement in sexual activity or exploitation of the inability to consent to sexual activity). The interpretation of neglect is as problematic as that of abuse. Neglect has been shown to be the most common form of mistreatment of older people. In New Zealand, neglect is generally defined as a result of another person failing to meet the physical and emotional needs of an older person. Further, self-neglect is defined as the behaviour of an elder which threatens his / her own health or safety (Age Concern New Zealand Inc., 2005). In summary, abuse includes physical, emotional, psychological, financial and sexual dimensions, and neglect (including self-neglect) can best be understood as a subset of abuse.

\section{Obstacles to the disclosure of abuse by older persons}

Elder abuse remained hidden and taboo until quite recently. During the early 1980s, more public and professional interest was given to the issue of elder abuse (McCreadie, 1996; 
2003; Pritchard, 1995). Despite the fact that the problem of elder abuse has gained more public attention and research, global statistics are still lacking. This may be due to the fact that in many instances health care and social welfare professionals continue to lack awareness and knowledge on how to deal with the issue and to take prompt action to protect the individuals subjected to abuse (Perel-Levin, 2008). Part of this underreporting is due to the complexity inherent in the phenomenon itself as abuse can take place in a wide range of settings, including hospitals, nursing homes, residential care homes, day centres and even the person's own home, perhaps the one place where the older person might feel safest (Abbey, 2009; Ansello \& O'Neill, 2010; Arai, 2006). Obstacles to disclosure may also include diminished capacity to comprehend, ignorance of the law or cultural differences which might result in the older person not recognising that an abusive situation is emerging. Dayton (2005) argued that in cases of elder abuse where the perpetrator is a caregiver, the client may present as protective towards the perpetrator and minimise the abuse due to shame or the fear of a negative outcome. Additional barriers to disclosure and help-seeking include fear of being placed in a care facility, sociocultural norms that discourage the involvement of outsiders in family issues, and a belief that there is little that the police or social agencies can do to help (Bergeron \& Gray, 2003; Fallon, 2006; Wahl \& Purdy, 2005). Furthermore, research indicates that abuse of older people is related to a shared living situation, social isolation, disease burden and caregiver strain (Lachs \& Pillemer, 2004). Family members, adult children or spouses are implicated in $90 \%$ of the cases of elder abuse. Other abusers include care professionals such as health or social workers, friends or neighbours. Sometimes the abusers or perpetrators do not recognise what they are doing as a form of abuse; different organisations and professionals still use different terminology. This causes significant issues for research as it makes it more challenging to compare the outcomes of various reports due to the inconsistencies in the definitions of elder abuse (Pillemer \& Prescott, 1989; Newton, 2010).

\section{The scope and correlates of elder abuse}

Many of the international studies have shed light on the scope and correlates of the elder abuse and mistreatment problem. For example, female gender (Biggs, Manthorpe, Tinker, Doyle \& Erens, 2009; Laumann, Leitsch \& Waite, 2008; Yaffe, Weiss, Wolfson \& Lithwick, 2007) and, in some cases, younger age (Biggs, et al., 2009; Klein, Tobin, Salomon \& Dubois, 2008) have been linked to higher rates of reported abuse. Family members have been identified in the majority of cases as the perpetrators (Acierno et al., 2010; Teaster, Otto, Dugar, Mendiondo, Abner \& Cecil, 2006). Other studies reported that adult children are often dependent on their victims for financial assistance, housing and other forms of support (Nerenberg, 2008). Age also appears to interact with health status to predict likelihood of mistreatment, such that younger elderly who are in poor health are more likely to experience abuse and mistreatment (Biggs et al., 2009) while other studies suggested positive associations between older age and elder mistreatment (Choi \& Mayer, 2000; Cooney \& Mortimer, 1995; Lachs, Williams, O’Brien, Hurst \& Horwitz, 1997). In addition, marital status such as divorce or separation and poor health status increased the likelihood of abuse and mistreatment (Biggs et al., 2009). Less participation in social activities was identified as a risk factor (Racic, Kusmuk, Kozomara, Develnogic \& Tepic, 2006), particularly among males (Yaffe et al., 2007). Other theories about mistreatment include victim vulnerability, dependency or impairment of the older person, personal characteristics of the elder (e.g., dementia, disruptive behaviours, trusting behaviours), significant needs for assistance, external stress (e.g., financial problems, job stress, additional family stress), intergenerational transmission of violence, intra-individual dynamics or personal problems of the abuser (e.g., alcoholism, 
drug addiction, emotional disorder) and stress on the part of the caregiver (Johannesen \& LoGiudice, 2013; National Centre on Elder Abuse, 2005).

The studies described above share some similarities to research conducted by Age Concern New Zealand. Each year, Age Concern New Zealand's Elder Abuse and Neglect Prevention (EANP) services receive more than 2,000 referrals for older people who may be facing elder abuse or neglect; that is about eight referrals every working day. Older people often experienced more than one type of abuse as Age Concern New Zealand reported over the last three years: 75\% involved psychological abuse, over 50\% involved financial abuse, 15-20\% involved physical abuse and 10-15\% involved neglect (Age Concern New Zealand Inc, 2015). Factors identified in a report prepared for the New Zealand Aged Care Association and Grey Power (2013) also identified which groups of older people are being abused and it notes that two thirds are women, $40 \%$ live alone, $80 \%$ of abuse is committed by members of family or whanau, over $40 \%$ of abusers are adult children and up to $35 \%$ of abusers are primary care givers. As the New Zealand population ages, the problem of elder abuse will continue to grow significantly. The New Zealand Age Residential Care Services Review in 2010 highlighted that the population over 65 years is estimated to increase by $84 \%$ from 512,000 to 944,000 in 2026 (Grant Thornton New Zealand Inc., 2010). Particularly important is the growth in people aged 85 or over, as they become medically fragile and / or cognitively impaired, increased physical, emotional and financial burdens on family members combined with increased vulnerability of the elderly people can create a dangerous environment in which elder abuse is a potential consequence.

Researchers have identified a wide range of factors associated with increased risk of elder abuse (Lachs et al., 1997; Schofield \& Mishra, 2003; Luo \& Waite, 2011). Elder abuse is a stressful life event that may lead to psychological distress. Several cross-sectional studies have shown that older adults who were abused and mistreated had higher levels of psychological distress than those who had no such experience (Comijs, Penninx, Knipscheer \& van Tilburg, 1999; Mouton, 2003). Clinical studies suggest other effects of elder abuse, including feelings of learned helplessness, alienation, guilt, shame, fear, anxiety, denial and post-traumatic stress syndrome (Wolf, 2000). Longitudinal studies found that risk factors for reported elder abuse included age, gender, race, poverty, functional disability and cognitive impairment (Lachs et al., 1997). Financial abuse was associated with having negative beliefs about their self-efficacy and a tendency to turn aggression and frustration on themselves (Comijs, Jonker, van Tilburg \& Smit, 1999). Elder abuse is also associated with a range of adverse health outcomes. It negatively impacts older adults' overall health and quality of life, resulting in psychological or emotional distress, depression, damage to self-confidence or self-esteem, pain and injury, decreased functional ability, increased dependency, loss of autonomy, withdrawal and social isolation (Choi and Mayer, 2000; Lachs, Williams, O'Brien, Pillemer \& Charlson, 1998; McDonald and Collins, 2000). It is well documented that stressful life events have detrimental effects on physical and mental health (Cohen, Janicki-Deverts \& Miller, 2007; Pearlin, Schieman, Fazio \& Meersman, 2005). Stress process theory contends that physical and emotional wellbeing is negatively associated with the number and frequency of stressful life events (Pearlin et al., 2005; Thoits, 1995). This theory suggests that experiencing multiple abuses and mistreatments in old age impacts more on wellbeing than experiencing one kind of mistreatment. This was consistent with Fisher and Regan's (2006) study of a clinical sample of community-dwelling older women who experienced multiple types of mistreatment, since they turned age 55, faced significantly higher odds of reporting depression or anxiety than other women who have not been abused. 
In conclusion, the study of elder abuse and mistreatment is given further imperative with an aging population, as does the number of studies outlining a close relationship between abuse and mental health, wellbeing and social adaptation in later life (such as Biggs \& Happala, 2010, Kurrle \& Naughtin, 2008; Lowenstein et al., 2009;). Elder abuse and mistreatment can be seen as both a medical and a social concern. It profoundly impacts the welfare of older adults in their physical and mental wellbeing. The social perception of abuse also acts more broadly in society; shaping expectations of care quality, the surveillance of informal care, and the discourse of older age (Harbison et al., 2012). In spite of the increased national and worldwide interest in elder abuse and mistreatment, there is a paucity of research data on the prevalence of elder abuse in New Zealand. Improving our understanding of the risk and protective factors for elder abuse and neglect will allow better prediction of situations where abuse or neglect are likely to happen.

\section{Method}

\section{Sample}

The sample used for this analysis was drawn from participants in the second wave (2012) of a large longitudinal study known as the New Zealand Longitudinal Study of Ageing (NZLSA), involving a population sample of 3,923 New Zealand adults aged 50-87 years (see http:/ / nzlsa.massey.ac.nz / for further information). All participants in this study were randomly selected from the New Zealand electoral roll for representativeness purpose. The NZLSA cohort profile, over-sampling process and recruitment of Māori respondents can be referred to previous studies (Towers, 2007; Towers \& Stevenson, 2014; Towers, Yeung, Stevenson, Stephens \& Alpass, 2014). A comprehensive postal questionnaire containing scales and questions on general health, social support, care-giving roles, financial wellbeing, neighbourhood characteristics and demographic information was sent to all participants. Study procedures were approved by the Massey University Human Ethics Committee (MUHEC Southern B $09 / 70$ ) and carried out in accordance with tenets of the Treaty of Helsinki.

Of the 3,923 questionnaires sent out, a total of 2,968 returned (78\% response rate). Sixty percent identified themselves as New Zealand European/Pakeha, while just over 35\% identified as Māori. They ranged in age from 50 to 87 years with a mean age of $66.1(+7.80)$, $55.1 \%$ were women, $26.8 \%$ were married / partnered and $19.2 \%$ reported living alone. Over $50 \%$ of the respondents reported having post-secondary or higher qualifications. The average personal income before tax was $\$ 34,615$ (after tax was $\$ 25,601$ ).

\section{Measures}

Nineteen specific variables were used for analyses in this study, respectively reflecting age; gender; marital status; living arrangement; education levels; ethnicity; personal income; elder mistreatment; physical health and mental health; economic wellbeing; depression; loneliness (social and emotional loneliness); total number of health conditions; ability to get around; satisfaction with life; and quality of life (QoL).

The elder mistreatment screening questions used in this study were from the original Vulnerability to Abuse Screening Scale (VASS) (Schofield \& Mishra, 2003), which was modified from an instrument developed previously (Hwalek \& Sengstock, 1986). In alignment with previous research (Dong, Simon \& Gorbien, 2007; Dong, Simon, Gorbien, Percak \& Golden, 2007), this study chose the following six validated questions for analysis. These are: (1) Are you afraid of anyone in your family? (2) Has anyone close to you tried to hurt or 
harm you recently? (3) Does someone in your family make you stay in bed or tell you that you are sick when you know you are not? (4) Has anyone close to you called you names or put you down or made you feel bad recently? (5) Has anyone forced you to do things you didn't want to do? and (6) Has anyone taken things that belong to you without your OK? These questions have been found to have high face validity for abuse and moderate to good construct validity. The scale was reported to have moderate internal consistency (Cronbach's alpha $=.60$ ) and that it is appropriate as a brief screening instrument (Schofield \& Mishra, 2003). A participant was considered as experiencing elder abuse or neglect if answering yes to any of the screening questions.

The SF-36 is a commonly used standardised health questionnaire consisting of 36 items and eight sub-scales (Ware, Kosinski \& Dewey, 2000). All scores are weighted so that they may be interpreted in the same direction (i.e. higher scores mean better health) and the subscales have been combined to provide two summary scores for physical and mental health respectively. These summary scores are normed and standardised so that the population mean is 50 .

Economic wellbeing was measured by the New Zealand Economic Living Standards Indicator (ELSI). The ELSI was developed in New Zealand to measure the levels of consumption, social activity and asset ownership, rather than the economic resources that enable them (Jensen, Spittal, Crichton, Sathiyandra \& Krishnan, 2002). The scale assesses restrictions in ownership of assets (eight items), restrictions due to cost in social participation (six items), the extent to which respondents economise (eight items) and a self-rated indicator of standard of living (three items). The scores on each of the items were combined to form a continuous variable ranging from 0 to 31 (higher scores reflect higher economic living standards).

The Centre for Epidemiologic Studies Short Depression Scale Short Form (CES-D-10) is a 10-item instrument that assesses depressive system (Anderson, Malmgren, Carter \& Patrick, 1994). The occurrence of each depressive symptom during the past week is rated on a scale of 0-3, with the total score ranging 0-30. A score of 10 is indicative of depressed mood.

The de Jong Gierveld Loneliness Scale (de Jong Gierveld, 1987) served as the measure of loneliness, which consists of 11 items. Participants respond to a directional statement to an emphatic disagreement with a neutral mid-point, ranging from 1 to 3 . The scores on each item were added together to produce a total loneliness score. The total loneliness scores ranged from 11 to 33, with higher scores meaning a higher level of loneliness. Six items, which consist of 'I miss having a really close friend', 'I experience a general sense of emptiness', 'I miss the pleasure of the company of others', 'I feel my circle of friends and acquaintances is too limited', 'I miss having people around' and 'Often, I feel rejected', represents emotional loneliness. Five items, including 'There is always someone I can talk to about my day-today problems', 'There are plenty of people I can lean on in case of trouble', 'There are many people that I can count on completely', 'There are enough people that I feel close to' and 'I can call on friends whenever I need them' represent social loneliness.

Single items were used to assess one's (a) ability to get around (How well are you able to get around? The options for responding were $1=$ very poorly, 2 = poorly, $3=$ neither poorly nor well, 4 = well, 5 = very well), (b) happiness (In general, how happy or unhappy do you usually feel? The options for responding ranged from $0=$ extremely unhappy to 10 extremely happy); (b) satisfaction with life at present (How satisfied are you with your life at present? The options for responding were $1=$ very dissatisfied to $5=$ very satisfied), and 
(d) perceived QOL (How would you rate your quality of life? The options for responding were 1 = very poor, 2 = poor, $3=$ neither poor nor good, $4=$ good, $5=$ very good). A list of 12 specified and one unspecified (i.e., 'other') chronic health conditions was presented to the participants. The number of those ticked as 'yes' were reported as a summed score labelled 'total health conditions'.

\section{Statistical analysis}

The IBM SPSS Statistical package (version 22.0, IBM SPSS Statistics for Windows, Released 2013, IBM Corp., Armonk, NY) was used for data entry and analysis. Descriptive data on the domains mentioned above were analysed for respondents who have experienced elder mistreatment and compared with those who did not experience elder mistreatment. Cross tabs with chi-square $\left(\mathrm{x}^{2}\right)$ were used to compare age groups, the proportion of men and women, marital status, living arrangement, education levels and ethnicity. Independent t-test was used to compare variables on personal income, health conditions, physical health, mental health, ability to get around, economic wellbeing, loneliness (social and emotional loneliness), depression, satisfaction with life and QoL between the two groups. As repeated measures across the groups could lead to an increased chance of making a Type I error, a Bonferroni adjustment was made to the alpha level to reduce that possibility as recommended (Tabachnick \& Fidell, 2007). As a result, the minimal level of significance was set at $\mathrm{p}<0.005$ (i.e. $0.05 / 19=0.003$ ) for these comparisons. Preliminary assumption testing was conducted to check for homogeneity of variances across groups before conducting this analysis (Tabachnick \& Fidell, 2007). This assumption was not violated.

\section{Results}

Elder abuse was found in $529(18.0 \%)$ of the participants. Table one provides details on comparison between older people who have experienced elder abuse/mistreatment and those who have not in relation to this demographic. There was a significant difference on age. Younger age groups between 60 and 64 , and 65 and $69(p=0.000)$ were significantly associated with elder abuse, although the effect size was small $\left(\phi_{c}=0.23\right)$. A total of $44 \%$ of the men and $56 \%$ of the women reported suffering abuse but no significant difference was found in gender among the two groups $\left(x^{2}=0.15, p=0.66\right)$. Marital status was found to have significant difference between the two groups with nearly $70 \%$ of those who were in married or partnered relationships reported to have experienced elder abuse $\left(x^{2}=8.30, p=0.000\right)$; however, it only represented a very small effect size $(\Phi=0.05)$. No significant differences were found on living arrangement $\left(x^{2}=0.51, p=0.43\right)$ and in education levels $\left(x^{2}=3.79, p=0.15\right)$. Significant difference was found in ethnicity $\left(x^{2}=51, p=0.000\right)$ with the mistreated group consisting of a high proportion of both New Zealand European/Pakeha (53.1\%), followed by Māori $(42.6 \%)$ but the effect size was moderately small $\left(\phi_{c}=0.13\right)$.

Table two illustrates the comparison of key variables between older people who have experienced elder mistreatment and those who have not. Significant differences were found among the following variables: personal income $(t[2817]=2.93, p=0.003)$, total number of health conditions $(t[597]=-7.64, p=0.000)$, physical health $(t[639]=4.93, p=0.000)$, mental health $(t[611]=12.83, p=0.000)$, ability to get around $(t[667]=7.35, p=0.000)$, economic wellbeing $(t[546]=12.91, p=0.000)$, loneliness $(t[671]=-14.48, p=0.000)$, depression $(t[675]$ $=-13.75, p=0.000)$, happiness $(t[663]=8.7, p=0.000)$, satisfaction with life $(t[690]=11.80$, $p=0.000)$ and QoL $(t[684]=13.09, p=0.000)$. The effect size on these key variables ranged from small to large $(0.15-0.77)$, in which loneliness has the largest effect size $(d=0.77)$, followed by economic wellbeing $(d=0.76)$, depression $(d=0.71)$ and mental health $(d=0.70)$. 
Such results indicated that older people who have experienced abuse tended to experience more loneliness and have more financial constraints. They were more likely to experience depression and mental health issues, which could contribute to higher levels of emotional and social loneliness. They were more likely to live with more health conditions which could have significant impact on their physical health and ability to get around. Overall, those who have experienced elder mistreatment tended to be less happy, and have poorer satisfaction with life and overall quality of life.

Table one. Demographic variables and elder abuse and mistreatment in community-dwelling older people in Aotearoa New Zealand.

\begin{tabular}{|c|c|c|c|c|c|}
\hline Variables & $\begin{array}{l}\text { Mistreated } \\
(\mathrm{n}=529) \\
\mathrm{n}(\%)\end{array}$ & $\begin{array}{l}\text { Not Mistreated } \\
\qquad(\mathrm{n}=2417) \\
\mathrm{n}(\%)\end{array}$ & Statistics & p-value & $\begin{array}{l}\text { Effect Size } \\
` \mathrm{~d}^{\prime} / \Phi / \phi_{\mathrm{c}}\end{array}$ \\
\hline $\begin{array}{l}\text { Age group } \\
50-54 \\
55-59 \\
60-64 \\
65-69 \\
70-74 \\
75-79 \\
80-84 \\
85 \text { and over }\end{array}$ & $\begin{array}{c}64(26.1) \\
67(22.6) \\
134(18.4) \\
116(18.2) \\
78(14.2) \\
50(14.9) \\
19(13.9) \\
1(5.6)\end{array}$ & $\begin{array}{l}181(73.9) \\
230(77.4) \\
594(81.6) \\
520(81.8) \\
472(85.8) \\
285(85.1) \\
118(86.1) \\
17(94.4)\end{array}$ & $X^{2}=26.34$ & 0.000 & $--/--/ 0.10$ \\
\hline $\begin{array}{l}\text { Gender } \\
\text { Male } \\
\text { Female }\end{array}$ & $\begin{array}{l}231(43.8) \\
297(56.3)\end{array}$ & $\begin{array}{l}1081(44.8) \\
1332(55.2)\end{array}$ & $X^{2}=0.15$ & 0.66 & --/0.01/-- \\
\hline $\begin{array}{l}\text { Marital Status } \\
\text { Married/Partnered } \\
\text { Other }\end{array}$ & $\begin{array}{l}361(68.2) \\
168(31.8)\end{array}$ & $\begin{array}{c}1800(74.5) \\
617(25.5)\end{array}$ & $\mathrm{X}^{2}=8.30$ & 0.000 & $--/ 0.05 /--$ \\
\hline $\begin{array}{l}\text { Living Arrangement } \\
\text { Alone } \\
\text { With others }\end{array}$ & $\begin{array}{l}108(20.4) \\
421(79.6)\end{array}$ & $\begin{array}{c}458(18.9) \\
1959(81.1)\end{array}$ & $X^{2}=0.51$ & 0.43 & --/0.01/ -- \\
\hline $\begin{array}{l}\text { Highest Qualification } \\
\text { No qualification } \\
\text { Secondary } \\
\text { Post-secondary \& higher }\end{array}$ & $\begin{array}{l}139(26.4) \\
106(20.2) \\
284(53.7)\end{array}$ & $\begin{array}{l}542(22.5) \\
533(22.1) \\
1342(55.5)\end{array}$ & $\mathrm{X}^{2}=3.79$ & 0.15 & $--/--/ 0.04$ \\
\hline $\begin{array}{l}\text { Ethnicity } \\
\text { NZ European/ Pakeha } \\
\text { Māori } \\
\text { Other }\end{array}$ & $\begin{array}{c}274(53.1) \\
220(42.6) \\
22(4.3)\end{array}$ & $\begin{array}{l}1599(67.3) \\
652(27.5) \\
124(5.2)\end{array}$ & $X^{2}=51.0$ & 0.000 & $--/--/ 0.13$ \\
\hline
\end{tabular}

Note: Ns will vary due to missing data

'd': small $=0.2$, medium $=0.5$, large $=0.8$

$\Phi$ : small $=0.1$, medium $=0.3$, large $=0.5$

$\phi_{c}:$ small $=0.07$, medium $=0.21$, large $=0.35$ 
Table two. Key variables and elder abuse and mistreatment in community-dwelling older people in Aotearoa New Zealand.

\begin{tabular}{|c|c|c|c|c|c|c|}
\hline & $\begin{array}{l}\text { Mistreated } \\
(\mathrm{n}=529)\end{array}$ & $\begin{array}{l}\text { Not Mistreated } \\
\quad(\mathrm{n}=2417)\end{array}$ & & & & \\
\hline Key variables & Mean(SD) & Mean(SD) & Statistics & p-value & $\begin{array}{l}\text { Effect } \\
\text { Size } \\
\text { 'd' }\end{array}$ & $\begin{array}{c}\text { Mean } \\
\text { difference } \\
\text { (CI) }\end{array}$ \\
\hline $\begin{array}{l}\text { Personal income } \\
\text { (before tax) }\end{array}$ & $\begin{array}{l}31,247.0 \\
(27,197.9)\end{array}$ & $\begin{array}{c}35,891.4 \\
(33,273.6)\end{array}$ & $t=2.93$ & 0.003 & 0.15 & $\begin{array}{c}4644.4 \\
(1533.93- \\
7754.29)\end{array}$ \\
\hline $\begin{array}{l}\text { Total number of } \\
\text { health conditions }\end{array}$ & $3.4(2.5)$ & $2.5(1.9)$ & $\mathrm{t}=-7.6$ & 0.000 & 0.25 & $0.9(-1.2-0.7)$ \\
\hline Physical health & $47.1(11.8)$ & $50.0(10.5)$ & $\mathrm{t}=4.9$ & 0.000 & 0.26 & $2.9(1.8-4.1)$ \\
\hline Mental health & $44.6(9.0)$ & $50.3(7.4)$ & $\mathrm{t}=12.8$ & 0.000 & 0.70 & $5.7(4.8-6.6)$ \\
\hline $\begin{array}{l}\text { Ability to } \\
\text { get around }\end{array}$ & $4.2(1.0)$ & $4.5(0.8)$ & $\mathrm{t}=7.4$ & 0.000 & 0.33 & $0.3(0.3-0.4)$ \\
\hline $\begin{array}{l}\text { Economic } \\
\text { wellbeing }\end{array}$ & $19.9(7.7)$ & $24.9(5.5)$ & $\mathrm{t}=12.9$ & 0.000 & 0.76 & $5.0(4.2-5.7)$ \\
\hline Loneliness & $18.1(5.3)$ & $14.5(4.1)$ & $\mathrm{t}=-14.5$ & 0.000 & 0.77 & $3.6(-4.1--3.1)$ \\
\hline Social loneliness & $8.5(2.9)$ & $6.9(2.3)$ & $t=-12.1$ & 0.000 & 0.62 & $1.6(-1.9--1.4)$ \\
\hline $\begin{array}{c}\text { Emotional } \\
\text { loneliness }\end{array}$ & $9.3(3.3)$ & $7.4(2.4)$ & $t=-12.6$ & 0.000 & 0.67 & $1.9(-2.1--1.6)$ \\
\hline Depression & $9.5(5.5)$ & $5.9(4.6)$ & $t=-13.7$ & 0.000 & 0.71 & $3.6(-4.1--3.1)$ \\
\hline Happiness & $7.0(2.1)$ & $7.9(1.7)$ & $\mathrm{t}=8.7$ & 0.000 & 0.45 & $0.9(0.7-1.1)$ \\
\hline $\begin{array}{l}\text { Satisfaction } \\
\text { with life }\end{array}$ & $3.7(0.9)$ & $4.2(0.8)$ & $\mathrm{t}=11.8$ & 0.000 & 0.59 & $0.5(0.4-0.6)$ \\
\hline Quality of life & $4.1(1.0)$ & $4.5(0.8)$ & $\mathrm{t}=10.8$ & 0.000 & 0.44 & $0.4(0.3-0.4)$ \\
\hline
\end{tabular}

Note: Ns will vary due to missing data

'd': small $=0.2$, medium $=0.5$, large $=0.8$

Table three presents the prevalence and types of elder abuse and neglect experienced by older people who reported being mistreated. The highest prevalence of abuse or neglect was emotional abuse (Has anyone close to you called you names or put you down or made you feel bad recently?) with $57.7 \%$, followed by financial exploitation (Has anyone taken things that belong to you without your OK?) with $49.3 \%$, physical abuse (Has anyone forced you to do things you didn't want to do? \& Has anyone close to you tried to hurt or harm you recently?) with $17.6 \%$ and $14.2 \%$ respectively. The coexistence of multiple forms of elder abuse was very common in this population. Of the abused older people, $65.8 \%$ suffered single forms of abuse, $18 \%$ suffered two forms of abuse and $16.2 \%$ suffered three or more forms of abuse. 
Table three. Prevalence and types of elder abuse.

Has anyone close to you called you names or put you down

or made you feel bad recently?

\section{$\mathbf{N}$}

305

261

93

75

74

32
$\%$

57.7

49.3

17.6

14.2

14.0

6.0

\section{Discussion}

This study represents the first large-scale population-based study of the prevalence of elder abuse in a community-dwelling setting in Aotearoa New Zealand. In this study, we found that elder abuse was common, with an estimated prevalence of $18.0 \%$. The present estimate of overall elder abuse was much higher than estimates obtained from international studies (Acierno et al., 2010; Laumann, Leitsch \& Waite, 2008). In addition to the overall prevalence, results from this study confirm that psychological and financial abuse are the most common types of elder abuse (Adams, Bagshaw, Wendt \& Zannettino, 2014; Age Concern New Zealand Inc, 2005; 2006; Lachs \& Pillemer, 2004).

Elder abuse is extremely complex and various factors contribute to its occurrence. In our study, we found that several factors were associated with elder abuse; loneliness, depression and being married/partnered significantly increased the risk of elder abuse. Lower satisfaction with life, poorer quality of life and feeling less happy were also common among older people who have experienced elder abuse. Our findings are similar to other studies (Dong, Beck \& Simon, 2009; Dong, Simon, Odwazny \& Gorbien, 2008), in which loneliness and depression were significantly associated with elder abuse. Our study also showed that older people who are married or partnered were more likely to be abused. Many studies have indicated that a shared living situation is a major risk factor for elder abuse and that people living alone are at lowest risk (Lachs et al., 1997; Pillemer \& Finkelhor, 1998). There are increased opportunities for contact and thus perhaps conflict and tension in a co-residential living arrangement.

Our study demonstrated that poor health status, particularly mental health, inability to get around and chronic illnesses impacted significantly on older people who experienced abuse. The inverse association between health status and elder abuse indicates that poorer health status may contribute to abuse in older people. We suspect that lower levels of health status may give rise to higher demand on support from spouse and family members. Caring for older people or spouses with poor health conditions requires substantial support and often personal sacrifices on the part of the caregivers and other family members (Garre-Olmo et al., 2009). This can put pressure on the caregiver's physical, psychological and economic status. It is possible that caregivers with excessive stress often fail to provide the necessary daily care to their elderly parents or spouse. In addition, there is a high likelihood that the stressed caregiver could be responsible for abuse and mistreatment. Elder abuse affects individuals' and families' need for services and supports, such as counselling or therapy, 
medication, hospitalisation, placement in long-term care facilities, or community-based or in-home health services (Dong, 2005; Lachs et al., 1998, 2002).

Previous research has indicated that gender, age, income and ethnicity are factors often associated with elder abuse. In contrast to the studies that suggest women are more likely to experience elder abuse (Acierno et al., 2007; Comijs et al., 1999; Laumann et al., 2008), gender differences were not found in this study. While abuse of older people affects both men and women (Acierno et al., 2010; Teaster et al., 2006), it is still noteworthy that over half of the older people who reported to have experienced elder abuse in this study were women. In our study, it was the younger age groups between 60 and 64, and 65 and 69 who were more likely to experience elder abuse as compared with the oldest older people. This finding is quite consistent with previous studies which yielded inconsistent results on the association between older age and elder abuse (Dong, Chen, Fulmer \& Simon, 2014). Despite these findings, Acierno and colleagues (2010) acknowledged that the exclusion of institutionalised older people may contribute to the lower rate of elder abuse and mistreatment among oldest older people. Future studies are needed to clarify the association between age and elder abuse. Finally, ethnicity was a significant factor in elder abuse in our study, in that those who reported abused were NZ European/Pakeha. This is consistent with a review completed by Hong, Leniston and Keys (2004) in New Zealand, which reported that most referrals to the Elder Abuse and / or Neglect Prevention (EANP) were non-Māori. Despite the current result demonstrating that NZ European/ Pakeha older people were at a higher risk for elder abuse, it does not mean there is necessarily less occurrence among Māori. Other factors may form an obstacle to reporting for Māori including being self-conscious and reluctant to reveal elder abuse and / or neglect and contact services for assistance (Amstadter, Zajac, Strachan, Hernandez, Kilpatrick \& Acierno, 2011; Hong, Leniston and Keys, 2004).

Results of this study reported that older people who experienced abuse were less financially secure and were worse off in their economic wellbeing than those who have not experienced abuse. This is consistent with the findings from Australian research into the abuse of older people that psychological and financial abuse, both nonphysical forms of abuse, are the types of abuse most likely to be experienced by people aged 65 years and older (Schofield, Reynolds, Mishra, Powers \& Dobson, 2002), and that older people are particularly vulnerable to financial abuse by people close to them (Faye \& Sellick, 2003; James, Grayar, $\&$ Mayhew, 2003). Some researchers have found that it is the older person's daughter or son who is most likely to commit abuse (Boldy, Horner, Crouchley, Davey, Kingley, \& Boylen, 2005 ; Faye \& Sellick, 2003; Livermore, Bunt \& Biscan, 2001), and that older women are more vulnerable to financial abuse than older men (Rabiner, O'Keeffe \& Brown, 2004).

The results of this study should be interpreted with limitations. First, this study did not examine the data by subtypes of elder abuse and mistreatment. It is suggested that the prevalence and severity of elder abuse may vary by the types of mistreatment (Cooney \& Mortimer, 1995). Also, a participant in this study was considered as experiencing elder abuse or neglect if answered yes to any of the screening questions. Future investigations should explore the prevalence, risk factors and outcomes associated with all types of elder mistreatment in New Zealand's aging population. Second, this was a cross-sectional study, and its results represented association between variables only, which limits our ability to make inferences regarding cause and effect among variables. Future studies are needed to explore the causal and temporal associations between the variables identified in this study. 
Third, our study was based on self-reports of elder mistreatment, which may have been subject to recall bias. Fourth, we did not have available data on the characteristics of potential abusers or perpetrators as research evidence has found that personality traits of potential perpetrators such as mental illness, alcohol and other substance abuse may be significantly associated with elder abuse and mistreatment (Compton, Flanagan \& Gregg, 1997; Fulmer, Guadano, Dyer \& Connolly, 2004; Reay \& Browne, 2001). Future studies could implement a dyadic or qualitative, face to face approach to understand elder abuse in a more comprehensive way. Fifthly, caution must be used when considering cultural interpretations of the data particularly for Māori because of the over-sampling procedure used in the original data collection (Towers et al., 2014). Finally, the study excluded those with cognitive impairment or living in institutions or residential care facilities, which limits its generalisability.

Elder abuse and mistreatment is common in the community-dwelling older people in New Zealand, and this study provides evidence for this increasingly common global public health issue. Despite several limitations, the current study has potential implications not only for community and hospital based human services professionals and organisations, but also for community policies concerning assessment, treatment and prevention strategies. Our study points to the need for improved investigations into elder abuse and mistreatment in Aotearoa New Zealand's aging population. Elder abuse and mistreatment most immediately affects the individual elder, but efforts for prevention and intervention must take other systemic factors into account if any efforts are to be sustained and successful. Scholars such as Payne (2008), and Teaster, Harley and Kettaneh (2014) suggested that the provision of services to elders requires a trans-disciplinary approach in order to develop effective interventions and relevant social policies in response to abuse and mistreatment. Professionals need better training around intervening with perpetrators, planning for the safety of elders and effective response strategies and collaborative training between domestic violence professionals, adult protective services and other human services professionals in order to gain a better understanding of human development and a lifespan perspective to improve the health and wellbeing of older people. Future study should also focus on providing support to mitigating caregiver stress experienced by family caregivers and to increase education for family caregivers to heighten their awareness of the rights of older care recipients, as well as the behaviours that are considered to constitute elder abuse.

\section{Conclusion}

While discussion continues on the definitions of elder abuse, neglect and mistreatment, it is clear from this paper that older people themselves are self-reporting these issues. Future work to assist both older people and the staff of both public and private services that they come into contact with could focus on training programmes, simple screening tools and clear pathways for intervention. Future work could also include the further development of public health strategies focused on the wider well-being of older people.

Acknowledgment. The New Zealand Longitudinal Study of Ageing (NZLSA) was funded by a grant from the New Zealand Ministry of Business, Innovation \& Employment (MBIE; formerly the Foundation for Research, Science and Technology).

\section{References}

Abbey, L. (2009). Elder abuse and neglect: When home is not safe. Clinics in Geriatric Medicine, 25, 47-60.

Adams, V.M., Bagshaw, D., Wendt, S., \& Zannettino, L. (2014). Financial abuse of older people by a family member: A difficult terrain for service providers in Australia. Journal of Elder Abuse E Neglect, 26(3), 270-290. 
Acierno, R., Hernandez, M.A., Amstadter, A.B., Resnick, H.S., Steve, K., Muzzy, W., \& Kilpatrick, D.G. (2010). Prevalence and correlates of emotional, physical, sexual, neglectful, and financial abuse in the United States: The national elder mistreatment study. American Journal of Public Health, 100(2), 292-297.

Acierno, R., Ruggiero, K.J., Galea, S., Resnick, H.S., Koenen, K., Roitzsch, J., ...Kilpatrick, D.G. (2007). Psychological sequelae resulting from the 2004 Florida Hurricanes: Implications for postdisaster intervention. Research E Practice, 97, S103-S108.

Age Concern New Zealand Inc. (2005). Age concern elder abuse and neglect prevention services: An analysis of referrals for the period: 1 July 2002 to 30 June 2004. Author, Wellington.

Age Concern New Zealand Inc. (2006). National action plan and national reference group report. Author, Wellington.

Age Concern New Zealand Inc. (2015). Elder abuse and neglect prevention. Retrieved from https: / / www.ageconcern. org.nz / ACNZPublic/Services / EANP/ACNZ_Public/Elder_Abuse_and_Neglect.aspx

Amstadter, A. B., Zajac, K., Strachan, M., Hernandez, M. A., Kilpatrick, D. G., \& Acierno, R. (2011). Prevalence and correlates of elder mistreatment in South Carolina: The South Carolina elder mistreatment study. Journal of Interpersonal Violence, 26, 2947-2972.

Anderson, E.M., Malmgren, J.A., Carter, W.B., \& Patrick, D.L. (1994). Screening for depression in well older adults: Evaluation of a short form of the CES-D. American Journal of Preventive Medicine, 10, 77-84.

Ansello, E.F., \& O'Neill, P. (2010). Abuse, neglect, and exploitation: Considerations in aging with lifelong disabilities. Journal of Elder Abuse \& Neglect, 22, 105-130.

Arai, M. (2006). Elder abuse in Japan. Educational Gerontology, 32 (1), 13-23.

Baker, A. A. (1975). Granny-battering. Modern Geriatrics, 5, 20-24.

Bergeron, L., \& Gray, L. (2003). Ethical dilemmas of reporting suspected elder abuse. Social Work, 48(1), 96-105.

Biggs, S., \& Haapala, I. (2010). Theoretical development and elder mistreatment: The management of socio-emotional boundaries. Ageing International, 35, 171-184.

Biggs, S., Manthorpe, J., Tinker, A., Doyle, M., \& Erens, B. (2009). Mistreatment of older people in the United Kingdom: Findings from the first national prevalence study. Journal of Elder Abuse E Neglect, 21, 1-14.

Boldy, D., Horner, B., Crouchley, K., Davey, M., \& Boylen, S. (2005). Addressing elder abuse: Western Australian case study. Australasian Journal on Ageing, 24(1), 3-8.

Burston, G. R. (1975). 'Granny battering.' British Medical Journal, 3(5983), 592.

Choi, N.G., \& Mayer, J. (2000). Elder abuse, neglect, and exploitation: Risk factors and prevention strategies. Journal of Gerontological Social Work, 33(2), 5-25.

Cohen, S., Janicki-Deverts, D., \& Miller, G.E. (2007). Psychological stress and disease. Journal of American Medical Association, 298, 1685-1687.

Comijs, H.C., Jonker, C., van Tilburg, W., \& Smit J.H., (1999). Hostility and coping capacity as risk factors of elder mistreatment. Social Psychiatry \& Psychiatric Epidemiology, 34, 48-52.

Comijs, H.C., Penninx, B.W.J.H., Knipscheer, K.P.M \& van Tilburg, W. (1999). Psychological distress in victims of elder mistreatment: The effects of social support and coping. Journal Gerontology: Social Sciences, 54B, S240-S244.

Compton, S.A., Flanagan, P., \& Gregg, W. (1997). Elder abuse in people with dementia in Northern Ireland: Prevalence and predictors in cases referred to a psychiatry of old age service. International Journal of Geriatric Psychiatry, 12, 632-35.

Cooney, C., \& Mortimer, A. (1995). Elder abuse and dementia - A pilot study. International Journal of Social Psychiatry, 41, 276-283.

Cooper, C., Selwood, A., \& Livingston, G. (2008). The prevalence of elder abuse and neglect: A systematic review. Age and Aging, 37, 151-160.

Dayton, C. (2005). Elder abuse: The social worker's perspective. Clinical Gerontologist, 28(1-2), 135-155.

De Jong Gierveld, J. (1987). Developing and testing a model of loneliness. Journal of Personality and Social Psychology, 53, 119-28.

Dong, X. (2005). Medical implications of elder abuse and neglect. Clinics in Geriatric Medicine, 21, $293-313$.

Dong, X., Beck, T., \& Simon, M.A. (2009). The associations of gender, depression, and elder mistreatment in a community-dwelling Chinese population: The modifying effect of social support. Archives of Gerontology and Geriatrics, 50, 202-208.

Dong, X., Chen, R., Fulmer, T., \& Simon, M. (2014). Prevalence and correlates of elder mistreatment in a community-dwelling population of U.S. Chinese older adults. Journal of Aging and Health, 26(7), 1209-1224.

Dong, X., Simon, M.A., \& Gorbien, M.J. (2007). Elder abuse and neglect in an urban Chinese population. Journal of Elder \& Abuse Neglect, 19(3-4), 79-96.

Dong, X., Simon, M.A., Gorbien, M., Percak, J., \& Golden, R. (2007). Loneliness in older Chinese adults: A risk factor for elder mistreatment. Journal of the American Geriatrics Society, 55, 1831-1835.

Dong, X., Simon, M.A., Leon, C.M., Fulmer, T., Beck, T., Evans, D. (2009). Elder self-neglect and abuse and mortality risk in a community-dwelling population. Journal of the American Medical Association, 302, 517-526.

Dong, X., Simon, M.A., Odwazny, R., \& Gorbien, M.J. (2008). Depression and elder abuse and neglect among a community-dwelling Chinese elderly population. Journal of Elder Abuse E Neglect, 20, 25-41.

Fallon, P. (2006). Elder abuse and/or neglect: Literature review. Wellington: Ministry of Social Development.

Faye, B., \& Sellick, M. (2003). Advocare's speak out survey 'S.O.S.' on elder abuse. Retrieved from http: / / apeawa. advocate.org.au/publications / Speak\%200ut\%20Survey\%20Final\%20Report.PDF. 
Fisher, B.S., \& Regan, S.L. (2006). The extent and frequency of abuse in the lives of older women and their relationship with health outcomes. Gerontologist, 46, 200-209.

Fulmer, T., Guadano, L., Dyer, C., \& Connolly, M.T. (2004). Progress in elder abuse assessment instruments. Journal of American Geriatric Society, 52, 297-304.

Garre-Olmo, J., Planas-Pujol, X., Lopez-Pousa, S., Juvinya, D., Vila, A., \& Vilalta-Franch, J. (2009). Prevalence and risk factors of suspected elder abuse subtypes in people aged 75 and older. Journal of the American Geriatric Society, 57, 815-922.

Grant Thornton New Zealand Inc. (2010). Aged residential care review. Auckland: Author.

Griffin, L.W. (1994). Elder maltreatment among rural African-Americans. Journal of Elder Abuse E Neglect, 6(1), 1-28.

Harbison, J., \& Morrow, M. (1998). Re-examining the social construction of 'elder abuse and neglect': A Canadian perspective. Ageing and Society, 18, 691-711.

Harbison, J., Coughlan, S., Beaulieu, M., Karabanow, J., VanderPlaat, M., Wildeman, S., \& Wexler, E. (2012). Understanding 'elder abuse and neglect': A critique of assumptions underpinning responses to the mistreatment and neglect of older people. Journal of Elder Abuse E Neglect, 22(2), 88-103.

Hong, B., Leniston, P., \& Keys, F. (2004). A review of elder abuse and neglect prevention services in New Zealand. Wellington: Office for Senior Citizens, Ministry of Social Development.

Hwalek, M. A., \& Sengstock, M. C. (1986). Assessing the probability of abuse in the elderly: Toward development of a clinical screening instrument. Journal of Applied Gerontology, 5, 153-173.

James, M., Grayar, A., \& Mayhew, P. (2003). A safe and secure environment for older Australians. Retrieved from http: / / www.aic.gov.au/publications / current $\% 20$ series / rpp/41-60/rpp51.html

Jensen, J., Spittal, M., Crichton, S., Sathiyandra, S., \& Krishnan, V. (2002). Direct measurement of living standards: The New Zealand ELSI scale. Wellington, New Zealand: Ministry of Social Development.

Johannesen, M., \& LoGiudice, D. (2013). Elder abuse: A systematic review of risk factors in community-dwelling elders. Age and Ageing, 42, 292-298.

Klein, A., Tobin, T., Salomon, A., \& Dubois, J. (2008). A statewide profile of abuse of older women and the criminal justice responses (NCJ 222459). Washington, DC: U.S. Department of Justice, National Institute of Justice.

Kosberg, J. I., \& Garcia, J. L. (1995). Common and unique themes on elder abuse from a world-wide perspective. Journal of Elder Abuse \& Neglect, 6, 183-197.

Kurrle, S., \& Naughtin, G. (2008). An overview of elder abuse and neglect in Australia. Journal of Elder Abuse $\mathcal{E}$ Neglect, 20(2), 108-125.

Lachs, M.S., \& Pillemer, K.A. (2004). Elder abuse. The Lancet, 364, 1263-1272.

Lachs, M.S., Williams, C., O’Brien, S., Hurst, L., \& Horwitz, R. (1997). Risk factors for reported elder abuse and neglect: A nine-year observational cohort study. Gerontologist, 37, 469-474.

Lachs, M.S., Williams, C., O’Brien, S., \& Pillemer, K.A. (2002). Adult protective service home use and nursing home placement. Gerontologist, 42, 734-39

Lachs, M.S., Williams, C.S., O’Brien, S., Pillemer, K.A., \& Charlson, M.E. (1998). The mortality of elder mistreatment. Journal of the American Medical Association, 280, 482-474.

Laumann, E.O., Leitsch, S.A., \& Waite, L.J. (2008). Elder mistreatment in the United States: Prevalence estimates from a nationally representative study. Journal of Gerontology, 63, S248-S254.

Lindert, J., de Luna, J., Torres-Gonzales, T., Barros, H., Ioannidi-Kopolou, E., Melchiorre, M.G., Soares, J. (2013). Abuse and neglect of older persons in seven cities in seven countries in Europe: A cross-sectional community study. International Journal of Public Health, 58, 121-132.

Livermore, P., Bunt, R., \& Biscan, K. (2001). Elder abuse among clients and carers referred to the Central Coast ACAT: A descriptive analysis. Australasian Journal on Ageing, 20(1), 41-47.

Lowenstein, A., Eisikovits, Z., Band-Winterstein, T., \& Enosh, G. (2009). Is elder abuse and neglect a social phenomenon? Data from the First National Prevalence Survey in Israel. Journal of Elder Abuse E Neglect, 21, $253-277$.

Luo, Y., \& Waite, L. (2011). Mistreatment and psychological well-being among older adults: Exploring the role of psychosocial resources and deficits. Journal of Gerontology, 66B(2), 217-229.

McCreadie, C. (1996). Elder abuse: Update on research. London: Age Concern and Institute of Gerontology.

McCreadie, C. (2003). The nature of elder abuse. In S. Amiel \& I. Heath. (Eds.), Family violence in primary care. Oxford: Oxford University Press.

McDonald, L., \& Collins, A. (2000). Abuse and neglect of older adults: A discussion paper. Health Canada, Ottawa: Family Violence Prevention Unit.

Mouton, C.P. (2003). Intimate partner violence and health status among older women. Violence Against Women, 9, 1465-1477.

National Centre on Elder Abuse. (2005). Fact sheet. Domestic violence: Older women can be victims too. Washington, DC: Author.

Nerenberg, L. (2008). Elder abuse prevention: Emerging trends and promising strategies. New York: Springer Publishing Company.

New Zealand Aged Care Association (NZACA) and Grey Power NZ Inc. (2013). An aged care commissioner in New Zealand. NZACA.

Newton, J.P. (2010). Elder abuse - an issue not to be ignored. Gerodontology, 27(2), 83-84.

Payne, B.K. (2008). Training adult protective services workers about domestic violence: Training needs and strategies. Violence Against Women, 14(10), 1199-1213. 
Pearlin, L.I., Schieman, S., Fazio, E.M., \& Meersman, S.C. (2005). Stress, health, and the life course: Some conceptual perspectives. Journal of Health $\mathcal{E}$ Social Behaviour, 46, 205-219.

Perel-Levin, S. (2008). Discussing screening for elder abuse at primary health care level. Geneva: WHO.

Pillemer, K., \& Finkelhor, D. (1998). The prevalence of elder abuse: Random sample survey. The Gerontologist, 28 , 51-57.

Pillemer K., \& Prescott, D. (1989). Psychological effects of elder abuse: A research note. Journal of Elder Abuse and Neglect, 1(1), 65-73.

Poole, C., \& Rietschlin, J. (2012). Intimate partner victimization among adults aged 60 and older: An analysis of the 1999 and 2004 general social survey. Journal of Elder Abuse E Neglect, 24, 120-137.

Pritchard, J. (1995). The abuse of older people (2nd ed). London: Jessica Kingsley Publishers.

Rabiner, D.J., O'Keeffe, J., \& Brown, D. (2004). A conceptual framework of financial exploitation of older persons. Journal of Elder Abuse \& Neglect, 16(2), 53-72.

Racic, M., Kusmuk, S., Kozomara, L., Develnogic, B., \& Tepic, R. (2006). The prevalence of mistreatment among the elderly with mental disorders in primary healthcare settings. The Journal of Adult Protection, 8, 20-24.

Reay, A.M., \& Browne, K.D. (2001). Risk factor characteristics in carers who physically abuse or neglect their elderly dependents. Aging \& Mental Health, 5, 56-62.

Schofield, M. J., \& Mishra, G. D. (2003). Validity of self-report screening scale for elder abuse: Women's health Australia study. Gerontologist, 43, 110-120.

Schofield, M.J., Reynolds, R., Mishra, G.D., Powers, J.R., \& Dobson, A.J. (2002). Screening for vulnerability to abuse among older women: Women's health Australia study. Journal of Applied Gerontology, 21(1), 24-39.

Shilling, D. (2010). Improving the court system's response to elder abuse. Victimization of the Elderly and Disabled, 11(49), 51-52, 62-63.

Tabachnick, B. G., \& Fidell, L. S. (2007). Using multivariate statistics (5th ed.). Boston, MA: Allyn and Bacon.

Teaster, P., Harley, D., \& Kettaneh, A. (2014). Aging and mistreatment: Victimization of older adults in the United States. The Collective Spirit of Aging Across Cultures, International Perspectives on Aging, 9, 41-64.

Teaster, P., Otto, J., Dugar, T., Mendiondo, M.S., Abner, E., \& Cecil, K. (2006). The 2004 survey of state adult protective services: Abuse of adults 60 years of age and older. Washington, DC: National Centre on Elder Abuse.

Thoits, P.A. (1995). Stress, coping, and social support process: Where are we? What next? Journal of Health $\mathcal{E}$ Social Behaviour, 35 (Special Issue), 53-79.

Towers, A. (2007). Health, work and retirement survey: Methodology. Retrieved 13 May, 2013, from http: / / hwr.massey. ac.nz/ resources/methodology_towers.pdf.

Towers, A. \& Stevenson, B. (2014). The New Zealand Longitudinal Study of Ageing, Summary Report - NZLSA Cohort Profile. Retrieved 5 May, 2015, from http:// www.massey.ac.nz/massey/fms/Colleges/College $\% 20$ of $\% 20$ Humanities\%20and\%20Social\%20Sciences / Psychology / HART / publications / reports / Cohort_profile_NZLSA_2014.pdf?A683FFE1BBBD233A08D293E9F20A97BA.

Towers, A., Yeung, P., Stevenson, B., Stephens, C. \& Alpass, F. (2014). Quality of life in indigenous and non-indigenous older adults: Assessing the CASP-12 factor structure and identifying a brief CASP-3. Quality of Life (first online): DOI 10.1007 / s11136-014-0756-y.

Wahl, J., \& Purdy, S. (2005). Elder abuse: The hidden crime. Toronto, ON: Advocacy Centre for the Elderly and Community Legal Education Ontario.

Ware, J. E., Kosinski, M., \& Dewey, J. E. (2000). How to score version 2 of the SF-36 Health Survey. Lincoln, RI: Quality Metric Incorporated.

Wolf, R. (2000). Introduction: The nature and scope of elder abuse. Generations, 24, 6-11.

World Health Organisation. (2002). Active ageing: A police framework. Geneva: Author.

World Health Organisation. (2011). Elder maltreatment, Fact sheet N³57, August 2011 (Available from: http:/ / www.who.int/mediacentre/ factsheets/fs357/en/index.html on dated July 12).

World Health Organisation (WHO). (2012). Aging and life course. Retrieved 24 March, 2014 from http: / / www.who. int/ageing/projects/edler_abuse/en

Yaffe, M.J., Weiss, D., Wolfson, C., \& Lithwick, M. (2007). Detection and prevalence of abuse of older males: Perspectives from family practice. Journal of Elder Abuse \& Neglect, 19, 47-60. 